\title{
Attitudes toward Seeking Professional Psychological Help: Adaptation and Evaluation of ATSPPH-SF using the Rasch Model
}

\author{
FA Nurdiyanto ${ }^{* 1}$, Ririn Mamiek Wulandari ${ }^{2}$, Griselda Maria Ancela Wodong ${ }^{3}$ \\ ${ }^{1}$ Faculty of Psychology, Universitas Gadjah Mada, ${ }^{1}$ Faculty of Psychology, Universitas Kristen Satya Wacana, \\ ${ }^{2}$ Faculty of Psychology, Universitas Gadjah Mada, ${ }^{2}$ Faculty of Psychology, Universitas Negeri Makassar, \\ ${ }^{3}$ Faculty of Psychology, Universitas Gadjah Mada, ${ }^{3}$ Faculty of Psychology, Universitas Negeri Manado
}

Submission 28 April 2021 Accepted 6 October 2021 Published 24 December 2021

\begin{abstract}
The availability of instruments for seeking professional help is crucial in identifying potential delays and failures to seek mental health help. The current study aims to adapt an Indonesian version of the Attitudes toward Seeking Professional Psychological Help-Short Form (ATSPPH-SF) scale and evaluate its psychometric properties using a Rasch modeling approach. Adaptation of the Indonesian scale was carried out in collaboration with a panel of experts under the guidelines of the International Translating Commission. The psychometric evaluation involved 951 respondents $(M=243, F=708)$ who participated through an online survey. The results of the Rasch modeling showed that the items of the Indonesian ATSPPH-SF had a good fit with the model. The response categories worked well and reliability was sufficient (item $=1$, respondent $=.59$, Cronbach's alpha=.67). This paper highlighted that the ATSPPH-SF Indonesia version is suggested to be valid and reliable. We concluded that ATSPPH-SF can be used in mental health professional help-seeking research in Indonesia.
\end{abstract}

Keywords: attitudes toward seeking professional psychological help-Short form (ATSPPH-SF); mental health; professional help-seeking; rasch model

Early treatment of mental disorders is crucial in obtaining maximum benefits from interventions. Having early treatment allows patients to receive assessment and diagnosis from professional workers, enabling more accurate interventions for treatment (Ibrahim et al., 2019). Seeking formal help from professional workers is considered more effective because the help is carried out by experts involved in delivering psychological services. Seeking formal help also constitutes a strategic coping means to respond to problems that cannot be managed individually (Panis et al., 2019; Rickwood \& Thomas, 2012).

Several instruments that measure help-seeking behaviors regarding mental health issues are currently available. For example, there exists the Willingness to Seek Help Questionnaire (Cohen, 1999), Inventory of Attitudes toward Seeking Mental Health Services (Mackenzie et al., 2004), or General Help-Seeking Questionnaire (GHSQ) (Rickwood et al., 2005). However, despite the availability of these instruments, they are rarely used, given the limited research on attitudes towards seeking help from mental health professionals. In addition, limited use of the instruments can also be attributed

*Address for correspondence: franznur@gmail.com 
to doubts of its effectiveness due to the different cultures of the populations included in past studies (Elhai et al., 2008).

Fischer and Turner (1970) developed the Attitudes towards Seeking Professional Psychological Help (ATSPPH-29) to evaluate a person's attitude in seeking psychological help from mental health professionals. Past studies have indicated that the ATSPPH-29 is a reliable measure in measuring attitudes toward seeking professional help, with consistent results in different samples and cultural settings (Nam et al., 2010; Picco et al., 2016). The scale was also used in a broader context not limited to the clinical setting (Park et al., 2018; Seidler et al., 2016), for example, in cultural assimilation processes (Leong et al., 2011).

Despite its importance in measuring help-seeking attitudes, the ATSPPH-29 has some limitations. Duncan (2003) reported low reliability with Cronbach alpha values of .5 on a number of the sub-aspects. Al-Darmaki (2003) and Williams et al. (2001) also found the factorial structure from the scale to be inconsistent when administered in a non-American sample. Professional psychological services are widely accepted in American society, while in non-American countries, help may be sought from traditional, social, or religious figures when overcoming psychological problems (Rickwood \& Thomas, 2012). Such findings indicate that the ATSPPH-29 has low reliability and an unstable factor structure. The ATSPPH-29 has also been criticized since it is an outdated instrument (Mackenzie et al., 2004). Wordings on the items are dated, and content validity from the scales is questioned since the items were produced decades ago. Consequently, some of the subscales may not fully explain the relevant domains pertaining to attitudes of seeking help (AEgisd'ottir \& Gerstein, 2009).

Fischer and Farina (1995) then modified ATSPPH-29 by developing the short version of the ATSPPH, which only included 10 items (ATSPPH-SF). Participants responded to each item with a scoring range from 0 (Disagree) to 3 (Agree). In developing the short form, Fischer and Farina (1995) used the same population demographic for the ATSPPH-29. Development of the ATSPPH-SF was made to increase the validity and reliability of the scale while also making it easier to administer. In contrast to the ATSPPH-29 with four factors, the short form consists of only a single factor to measure attitudes toward seeking professional psychological help. The scale showed an internal consistency of .84. Fischer and Farina (1995) mentioned that using the single-factor solution was most suitable because it represents the overall dimensions of attitudes toward seeking help.

Evaluation of the psychometric properties of the ATSPPH-SF has shown mixed results. Fang et al. (2011) performed CFA on a sample of Chinese participants using the instrument. Fang et al. (2011) then performed an exploratory model with two factors, namely confidence in the value of counselling and motivation for seeking counseling, with suggested seven items were left with minimally adequate factors. The results of the analysis showed that the reliability of the instrument was very low. Picco et al. (2016) also evaluated the psychometric properties of the ATSPPH in the multiethnic context of Singapore. The instrument showed good reliability with a 3-factor structure: openness to seeking professional help, value in seeking professional help, and preference to cope on one's own. Finally, an evaluation conducted by Rayan et al. (2020) showed that the single factor solution of the ATSPPH-SF 
also showed good internal consistency and convergent validity.

The ATSPPH-SF has been used extensively in the literature to understand individual attitudes in seeking professional psychological help. Although this instrument has been used cross-culturally, there are some limitations concerning accuracy in measuring attitudes. Further investigation is needed to test the reliability of the ATSPPH-SF among different cultures. Accordingly, the current study aimed to adapt and validate the ATSPPH-SF scale within an Indonesian sample.

Considering the reliability of the ATSPPH-SF in measuring help-seeking attitudes, it is crucial to adapt and validate the instrument to be applicable for the Indonesian language and culture. The availability of the ATSPPH-SF becomes an alternative to measure attitudes in the study of seeking professional psychological help since it is practical and easy to administer. This research is conducted to adapt and evaluate the psychometric properties of the ATSPPH-SF among an Indonesian sample. This research was conducted in two stages: First, the adaptation of the Indonesian version of the ATSPPH-SF and then testing the psychometric properties using a Rasch model (Bond \& Fox, 2015). The Rasch model was chosen because it provides information on the respondents and the items through a calibration process.

\section{Method}

\section{Research Design}

This research used a quantitative approach focusing on psychometric analysis to evaluate the characteristics of psychological measurement. This research was initiated by an adaptation of the scale to Indonesian and then followed by an evaluation of its psychometric properties.

\section{Stage 1: Indonesian Adaptation of ATSPPH-SF}

The adaptation adhered to the guidelines of the International Test Commission (2018). The first phase of the study was to obtain permission from Professor Fisher to adapt the scale. It was then followed by the organization of a seminar with an expert panel to discuss the definition, content, and constructs and adjust the format of the scale to suit the target population. The adaptation phase consisted of five stages: 1) Translation of the ATSPPH-SF to Indonesian. Two Indonesian translators were recruited (T-1 and T-2), who had equivalent English proficiency IELTS score $>$ of 7 and had a background in psychology; 2) Reconciliation panel, the translators synthesized the results of the translation based on the original scale and the translated scale, to produce a combined translation (T-12); 3) The T-12 scale was then translated back into English by two translators who have excellent English skills evidenced by IELTS score higher or equivalent to 7 (BT-1 and BT-2). The result of the backward translation was then discussed with the scale developer to evaluate the accuracy of the meanings; 4) The Panel (PA) discussed all scale versions (original, T-12, \& BT-12) and developed the pre-final version for the field test. Discussions were conducted by the expert panel that consisted of an expert in psychometrics, clinical psychology, Indonesian language, and English language. The discussion results formed a decision for the expert panel to establish the equivalence of the original scale and the adapted scale on 
the semantic, idiomatic, and conceptual aspects; 5) Readability was evaluated by involving a number of participants that have characteristics of the target population.

\section{Stage 2: Evaluation of Psychometric Properties of the ATSPPH-SF}

The psychometric properties were evaluated using the Rasch model using the Rating Scale Model (RSM). The psychometric properties included unidimensionality, local independence, consistency between items and respondents, functioning of scale ranks, item-respondent map, reliability (items, respondents, and alpha Cronbach), and Differential Item Functioning (DIF). The degree of item and respondent consistency was used to identify the item, and respondent accuracy with the model using infit means-square, outfit means-square (MNSQ), and point measure correlation (PTMEA). A perfect score for the infit and outfit values on MNSQ is 1, or ranges from .5 -1.5 (Boone et al., 2014), while for the item discriminant power or PTMEA as large as $>.20$ which implies adequately discriminative (Alagumalai \& Curtis, 2005). The criteria which were used in the measurement of reliability was the Alpha Cronbach, which was .6, which was adequate according to the guidelines. In contrast, Ursachi et al. (2015) gave a range from .6-.7, which was the general standard for internal consistency levels for adequate reliability of a scale. The reliability for the items was as large as .67 , which was considered adequate (Sumintono \& Widhiarso, 2014). Furthermore, bias detection of items based on gender can be observed from the probability of items that were $p<5 \%$.

\section{Research Participants}

Participants were aged between 19-50 years and lived in Indonesia. This research recruited 1077 respondents; however, 126 of their data were not analyzed because they were incomplete. Accordingly, 951 respondents were included in the analyses, and they came from different islands in Indonesia. Respondents were recruited using accidental sampling and were asked to complete an online survey. Specifically, $74.45 \%$ of participants were women $(n=708)$ and 243 men $(25.5 \%)$ and their ages were between 19-50 (Means = 24.2; $\mathrm{SD}=4.1$ ). This research was approved by the Ethical Committee of the Faculty of Psychology Universitas Gadjah Mada (approval date: 9 February 2021, Number: 1016/UNI/FPSi.1.3/SD/PT.01.04/2021). The respondents have received research information, and we obtained consent from all participants.

\section{Data Collection}

Data was collected using the ATSPPH-SF (Fischer \& Farina, 1995), which was adapted from stage 1 of the research. The scale was composed of two aspects which consisted of stage 1) Openness to seek professional help, which consisted of 3 items, for example, "If I thought I was having a mental breakdown, my first thought would be to get professional attention", 2) Evaluations for seeking professional help which consisted of 4 items, for example, "I admire people who are willing to cope with their problems and fears without seeking professional help", and 3) Choices to solve their problems which consisted of 3 items for example "Given the amount of time and money involved in psychotherapy, I am not sure that it would benefit someone like me". This scale was used for four 
response categories, namely Disagree (0), Partly Disagree (1), Partly Agree (2), and Agree (3). Data collection was conducted online using Google Forms. The instrument was shared through numerous social media channels and influencers.

\section{Data Analysis}

Data analysis was conducted using Rasch Modelling in three stages. The first stage was conducted by eliminating respondents who were categorized as misfits based on person fit order. When the data was clean from outliers, this was followed up by the second stage using the RSM assumption tests, namely unidimensionality and local independence. After testing for these assumptions, the Rasch Model was conducted to evaluate the psychological properties of the ATSPPH-SF scale. In addition, this study also applied the classical test approach in testing reliability using Cronbach alpha. All of the analyses were conducted using the software Winstep version 3.73 .

\section{Results}

\section{Stage 1: Adaptation of the ATSPPH-SF into Bahasa Indonesia}

The instructions and items of the ATSPPH-SF were relatively easy to translate into Indonesian. There were minor differences between the translators in the expression of the language. For example, emotional problems (item 7) was translated by T-1 as emotional problems, while T-2 translated it as emotional issues. The reconciliation panel (T-12) agreed to use emotional problems while adjusting the wording with the context of the item as well as the social context. The results of the reconciliation T-12 were then back-translated into English. Furthermore, the BT-12 version was discussed with the original scale developer and judged whether the BT-12 measures the same construct as the original version. Tests of readability on the adapted scale involved 30 participants to evaluate whether the item's instructions could be understood. All participants mentioned that the adapted scale could be understood. 
Nurdiyanto et all || Attitudes toward Seeking Professional

Table 1

Sample of items that were translated

\begin{tabular}{|c|c|c|c|c|}
\hline No & Original Item & T-12 & BT-12 & PA \\
\hline \multirow{7}{*}{4} & & mengagumi & & mengagumi \\
\hline & I aamire people who & orang-orang yang & I admire people who & orang-orang \\
\hline & are willing to cope & menangani & want to deal with & menghadapi \\
\hline & with their problems & masalah dan & their problems and & masalah dan \\
\hline & and fears without & ketakutan mereka & fears without seeking & ketakutan mereka \\
\hline & seeking professional & tanpa mencari & professional help. & tanpa mencari \\
\hline & . & bantuan profesional & & bantuan profesional. \\
\hline \multirow{4}{*}{6} & I might want to & Saya mungkin & I might want to & Saya akan mencari \\
\hline & have psychological & akan memperoleh & have psychological & layanan konseling \\
\hline & counseling in the & konseling psikologis & counseling in the & psikologis \\
\hline & future. & di kemudian hari. & $\begin{array}{l}\text { future. } \\
\text { People should }\end{array}$ & kemudian hari. \\
\hline \multirow{13}{*}{9} & & & solve their own & \\
\hline & & & problems, which is & \\
\hline & & Orang-orang & why psychological & \\
\hline & People should & seharusnya & counseling should & \\
\hline & solve their own & menyelesaikan & be a last resort. & \\
\hline & problems, therefore, & masalahnya sendiri, & \& $\quad$ Orang-orang & \\
\hline & getting psychological & karena itu, konseling & seharusnya dapat & \\
\hline & counseling would be & psikologis akan & menyelesaikan & \\
\hline & their last resort. & menjadi pilihan & masalahnya sendiri, & \\
\hline & & terakhir mereka. & sehingga konseling & \\
\hline & & & psikologis semestinya & \\
\hline & & & menjadi pilihan & \\
\hline & & & terakhir. & \\
\hline
\end{tabular}


Stage 2: Evaluation of psychometric properties ATSPPH-SF Indonesian version

The Rasch Modelling produced information about the instrument, items, and respondents. Analysis was conducted numerous times to meet the consistency of the items with the Rasch model. At the first stage, Person Fit Order was applied to eliminate misfit respondents using the formula $\underline{x}+\mathrm{SD}$, which was then compared with the logit values of the respondents. Analysis of the Person Fit Order produced a logit score of 1.8. As many as 126 respondents were identified as outliers because they showed logit scores higher than 1.8. For example, respondent 14 with the response "333332333" was judged as a misfit. Respondent 14 had a unique response pattern by answering 3 (Agree) for item 04, which was the most difficult item to agree with, and answered 2 (Partly Agree) for items that were easily agreed with. Following this screening process, 951 respondents were viewed as fit for further analyses. In the second stage, analysis was conducted to items that were misfits/outliers of the model. Infit, mnsq, outfit mnsq, and PTMEA were used as criteria to evaluate item accuracy within the Rasch model. At this stage, all items were evaluated to see whether they had a good fit with the Rasch model (See Table 2).

\section{Table 2}

Item Accuracy

\begin{tabular}{cccccc}
\hline Item & $\begin{array}{c}\text { Item } \\
\text { Measure }\end{array}$ & $\begin{array}{c}\text { Infit } \\
\text { MNSQ }\end{array}$ & $\begin{array}{c}\text { Outfit } \\
\text { MNSQ }\end{array}$ & PTMEA & \\
\hline A4 & .88 & 1.17 & 1.15 & .49 & Fit \\
A9 & .84 & 1.06 & 1.06 & .53 & Fit \\
A8 & .64 & .99 & 1.02 & .49 & Fit \\
A10 & .41 & 1.02 & 1.03 & .50 & Fit \\
A5 & -.05 & .79 & .79 & .62 & Fit \\
A2 & -.33 & 1.03 & 1.05 & .48 & Fit \\
A1 & -.35 & 1.04 & 1.03 & .53 & Fit \\
A6 & -.38 & .93 & .95 & .48 & Fit \\
A7 & -.40 & 1.08 & 1.11 & .42 & Fit \\
A3 & -1.26 & .78 & .78 & .54 & Fit \\
\hline
\end{tabular}

The results of the final analysis yielded a raw variance explained by measures of $37.2 \%$ $(>20 \%)$, unexplained variance $12.4 \%$ and $8.6 \%(<15 \%)$, which showed that the requirements for unidimensionality for the scale ATSPPH-SF had been met (Sumintono \& Widhiarso, 2014). In other words, the ATSPPH-SF scale has a single dimension in measuring attitudes toward seeking professional psychological help. The second criterion was the assumption of local independence. It means that the respondents' performance in working on an item was unrelated to performance on other items. Local independence required that item pairs were not recommended to have raw residual 
correlations above .30. The results of the local independence analysis showed that all item pairs had a residual correlation below .30, indicating that all items were free from local dependence (see Table 3).

Table 3

Item and Respondent Statistics

\begin{tabular}{|c|c|c|}
\hline & Output & Result \\
\hline \multirow{15}{*}{ Item } & Item reliability & 1 \\
\hline & Separation Index & 14.87 \\
\hline & Strata $(\mathrm{H})$ & 20.16 \\
\hline & Max & .88 \\
\hline & Min & -1.26 \\
\hline & Residual corr A05 - A09 & -.28 \\
\hline & Residual corr A01 - A10 & -.27 \\
\hline & Residual corr A04 - A06 & -.25 \\
\hline & Residual corr A05 - A10 & -.25 \\
\hline & Residual corr A01 - A09 & -.25 \\
\hline & Residual corr A03 - A09 & -.25 \\
\hline & Residual corr A02 - A09 & -.24 \\
\hline & Residual corr A04 - A07 & -.22 \\
\hline & Residual corr A03 - A10 & -.22 \\
\hline & $\begin{array}{l}\text { Residual corr A07 - A08 } \\
\text { Mean }\end{array}$ & $\begin{array}{l}-.22 \\
.56 \text { Logit }\end{array}$ \\
\hline \multirow{6}{*}{ Respondent } & $\mathrm{SD}$ & .72 \\
\hline & Respondent reliability & .59 \\
\hline & Separation Index & 1.21 \\
\hline & Strata $(\mathrm{H})$ & 1.94 \\
\hline & Max & 2.30 \\
\hline & $\begin{array}{l}\text { Min } \\
\text { Alpha Cronbach }\end{array}$ & $\begin{array}{c}-2.67 \\
.67\end{array}$ \\
\hline \multirow{3}{*}{ Instrument's } & Raw variance explained by measures & $37.2 \%$ \\
\hline & Unexplained variance in 1 st contrast & $12.4 \%$ \\
\hline & Unexplained variance in 2 nd contrast & $8.6 \%$ \\
\hline
\end{tabular}

The analysis results showed that all ten items fit with the Rasch model and were of good quality. Reliability tests produced a value of 1 (very good). However, the respondents' reliability was low with a value of .59 , with Cronbach's alpha was .67 , which was reasonably sufficient. The scores of PTMEA produced values ranging from .42-.62, which meant that all items could differentiate the level of abilities of the respondents. The classification of item and respondent could be seen through the separation of strata: $\mathrm{H}=\{((4 \mathrm{x}$ index separation $)+1) / 3\}$. The item's separation index was 20.16, which meant that the total number of respondents in this measure was excellent to confirm the item's difficulty level. Furthermore, the respondents' separation index was 1.95 (rounded off to 2), which 
meant that the instrument was not sufficiently sensitive to differentiate between respondents with high or low responses. The higher the $\mathrm{H}$ value, the better it can detect respondent groups and item groups in a broader sense.

\section{Figure 1}

Wright Map

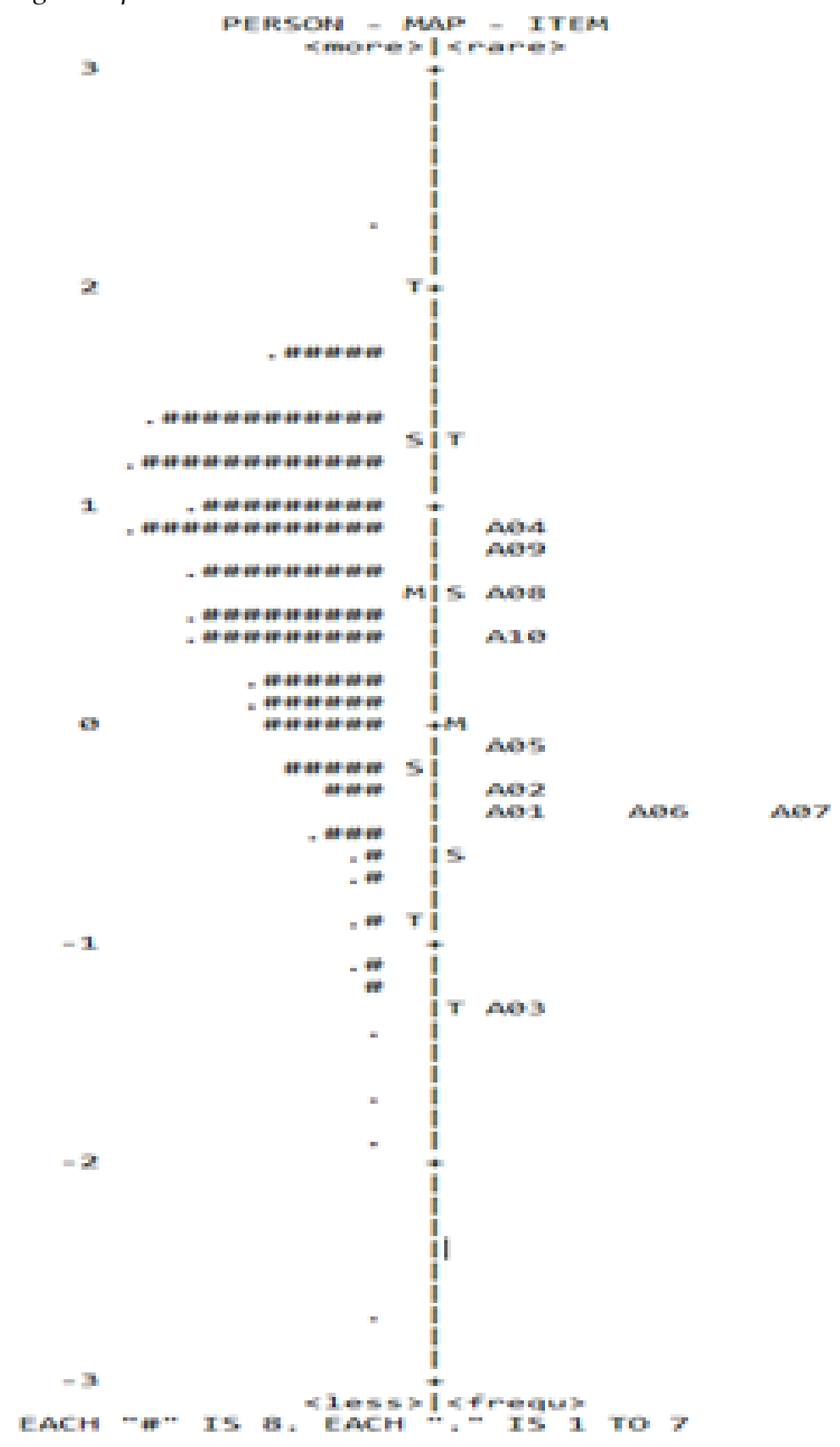




\section{Nurdiyanto et all \| Attitudes toward Seeking Professional}

Figure 1 shows the Wright Map, which is a map of item-respondent on the same scale. The average score for the respondents was $.56 \operatorname{logit}(S D=.72)$ which showed that on average the probability of the respondents in ATSPPH-SF was higher than the difficulty level of the item (0 logit). Furthermore, the distribution of the respondents ranged from $-2.67-2.30$ which exceeded the range of item difficulty -1.26 - .88. The Wright Map also showed no items that could discriminate respondents on a specific difficulty level, which led to the measurement scores at those levels having low reliability.

\section{Figure 2}

Test Information Function

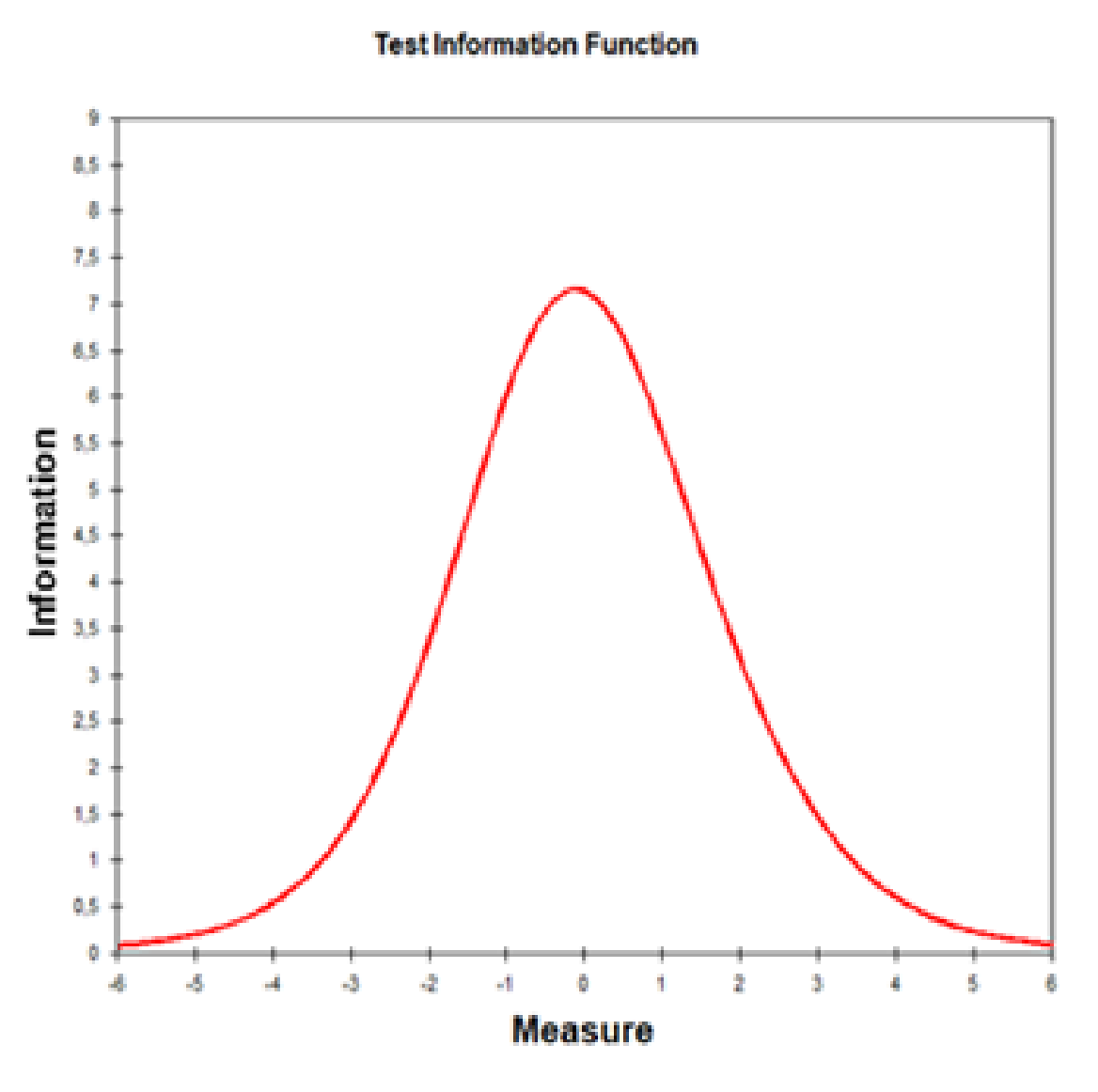

Figure 2 showed the results of the Test Information Function (TIF) results, which provided information concerning the instrument's relevance with the respondents' ability. The results of the TIF showed that the peak of the curve was on the ability level -.12 logit, which meant that this instrument would give maximum information when it was given to respondents with the level of seeking for professional psychological help at the mild level or around -.3 to .06 logit. 
Figure 3

Differential Item Functioning
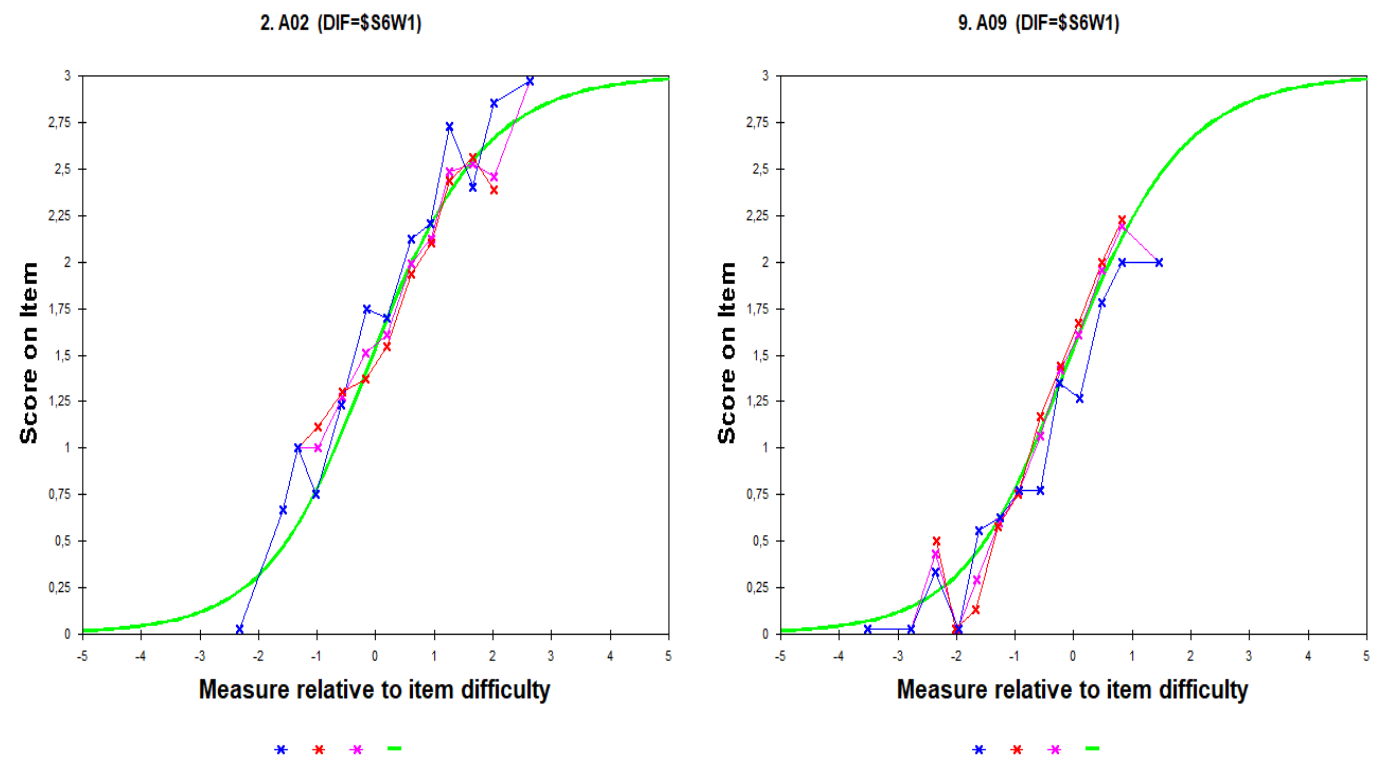

This model evaluated the potential bias of gender in the ATSPPH instrument-SF using the Differential Item Functioning (DIF) test. Items with probabilities $<.05$ can be categorized as having bias. DIF tests found that A02 $(\mathrm{p}=.042)$ and A09 $(\mathrm{p}=.002)$ were detected to have gender bias. It suggested that male and female participants did not have the same probability of obtaining high scores on both items. The statement on A02 showed the highest score among men, while statement A09 had the highest score for female participants.

Table 4

Functionality of the Ranking Scales

\begin{tabular}{ccccc}
\hline $\begin{array}{c}\text { Observed } \\
\text { Average }\end{array}$ & $\begin{array}{c}\text { Andrich } \\
\text { Threshold }\end{array}$ & Infit MNSQ & $\begin{array}{c}\text { Outfit } \\
\text { MNSQ }\end{array}$ & Category \\
\hline-.63 & NONE & .98 & 1.00 & 0 (Disagree) \\
.06 & -.86 & .97 & .95 & 1 (Partly Disagree) \\
.66 & -.22 & .97 & .96 & 2 (Partly Agree) \\
1.21 & 1.08 & 1.06 & 1.05 & 3 (Agree) \\
\hline
\end{tabular}

Table 4 showed that the scores for the observed average started from -.63 for the response category 0 (Disagree) and consistently increased to 1.21 logit for the choice category (Agree). The consistent increase can be seen from the Andrich Threshold from NONE to 1.08 logit. The scores for the infit mnsq and outfit mnsq ranged from .5-1.5, meaning that all response categories on this scale were following the model, and there was no noise in the measurement. In other words, the polytomous item responses used for the response category ATSPPH-SF were already correct. 


\section{Nurdiyanto et all \| Attitudes toward Seeking Professional}

\section{Discussion}

Although the instrument measuring attitudes toward seeking help has been widely known in Indonesia, evaluation of this instrument and its psychometric properties has rarely been conducted. This research was conducted to adapt the ATSPPH-SF to Indonesian and evaluated based on an Indonesian sample. The Rasch model was applied to evaluate the scale's accuracy and overcome issues concerning different metrics between items. The scores which were produced have a pure score and are free from measurement error.

This adaptation resulted in the Indonesian ATSPPH-SF, which was well understood by the respondents and had excellent psychometric properties. This adaptation considered the views of a panel of experts to ensure that the terms used were accurate with the context of the local culture. For example, the panel of experts preferred to use the term gangguan mental (mental disorder) as opposed to gangguan jiwa because it is more popular in society and has fundamental differences with neurocognitive disorders or intellectual deficiencies.

The assumptions of unidimensionality and local independence were met with the RSM approach. All items from the Indonesian version had good fit with the Rasch Model. All values of infit mnsq, outfit mnsq on the items met the Rasch criteria and also had satisfactory discriminant power. Azwar (2018) suggested that items with a high discrimination index could distinguish which person or group has the attribute and who does not.

The reliability of the item from the Rasch Model analyses showed that the Indonesian ATSPPH-SF had a value of 1 . This suggests that the items would function well when given to respondents with equivalent abilities (Bond \& Fox, 2015). However, the reliability of the respondents showed that the lowest score was .59. It means that the estimation of the consistency of the respondents would be weak if they were asked to work on another instrument which consisted of items that measured the same constructs of the ATSPPH-SF. This was consistent with the reliability value with a Cronbach alpha of .67. The reliability of the respondents was equivalent with the alpha Cronbach of .59. The low reliability of respondents and alpha could be caused by homogeneous respondent classification and the small number of items. Nunnaly and Bernstein (1994) explained that the alpha could influence the length of the test. The shorter the test, the lower the alpha values tend to be. This study analyzed that the score of Index Separation Respondents was only 2 with a small number of items (10 items). Although the alpha value was .67; Ursachi et al. (2015) viewed that alpha values of .6-.7 can be accepted.

A03 "If I were experiencing a serious emotional crisis, I would be sure that psychotherapy would be useful" was the item which was easiest for the respondents to agree with (-1.26 logit score). Serious psychological problems allow more professional interventions compared to everyday problems. A04 "I admire people who are willing to cope with their problems and fears without seeking professional help" was the item that was most difficult to agree with (.88 logit score). A04 contained specific attitudes on other people's behaviors in utilizing professional assistance, while not every person agrees with this action when people experience psychological issues. 
The RSM approach in the Rasch model also showed abilities in differentiating the four response categories of the ATSPPH-SF. The average estimation for each response category increased, which was in line with the predicted direction. The response categories also moved consistently from the lower to the higher response categories. The threshold for the response categories, which were close together, also increased in line with predictions. This suggests that the metric distance of the threshold that differentiates between the categories 0 and 1, 1 and 2, and category 2 and 3, were equivalent among all items (Tennant \& Conaghan, 2007). In addition, the four response categories showed infit values and outfit mnsq that can be accepted. The validity of the ranking scale was one form of the advantage in using the Rasch Modelling (Smith et al., n.d.; Tennant \& Conaghan, 2007).

The Indonesian version of the TIF shows that this instrument can provide maximum information if given to respondents with moderate ATSPPH-SF abilities. Information on measurement results is relatively low if given to respondents with low to deficient ATSPPH-SF levels. The same result could occur when this instrument was given to people with high to very high abilities; therefore, the obtained of ATSPPH-SF information was relatively low.

This study found that some items were gender biased (A02 and A09). One of the advantages of the RSM approach was that the Rasch model can detect DIF. The instrument users could check whether the DIF was considered a validity threat that would need further treatment (Zanon et al., 2016). DIF occurs because respondents with identical latent characteristics gave distinct response categories that were different on numerous items. In the current study, the DIF analysis was conducted based on sex. The DIF results showed that male and female students did not have the same chance to obtain high scores for the items A02 and A09.

For A02 "Talking about problems with a psychologist seems to me as a poor way to get rid of emotional problems" showed that men tend to show higher scores compared to women respondents. This bias occurs because men were considered as strong and independent figures, and so therefore in overcoming their personal problems they do not require professional help. Call and Shafer (2018) and Roskar et al. (2017) found that men from numerous age groups and social and ethnic backgrounds tend to have low scores for seeking professional help. The norms among a masculine society constructed a man to be a figure who was strong and independent. Men were more willing to psychological help for personal needs instead of emotional access (Vogel et al., 2011). They were reported having difficulty recognizing and expressing their emotional problems (Lynch et al., 2018).

This study found that the score A09 "People should solve their own problems, therefore, getting psychological counseling would be their last resort" was higher among women compared to male participants. This study emphasized that female respondents often bear the burden in meeting gender expectations, particularly concerning gender roles in the household and public sector (Fung \& Wong, 2007). Women were reported to experience higher stress and psychological problems compared to men (Chang et al., 2012). In addition, in dealing with the household, women work to meet social and economic demands that make it difficult for them to find the right time to seek professional help, which may lead to the development of symptoms that become increasingly severe (Sheikh \& Furnham, 2000).

Determinants of attitudes to seeking help were influenced by numerous factors, such as social, 
cultural, and individual characteristics. Most of the cultures in Indonesia consider psychological therapy as ineffective in treating disorders and mental illness, and therefore they prefer to resort to traditional approaches (Marchira et al., 2016). Cultural prejudice also relates with mental disorders and some vulnerabilities of the self and strong negative stigma (Staiger et al., 2017). Such perceptions make individuals choose to solve their emotional problems alone rather than asking help from other people including professional workers (Yu et al., 2015). Insufficient knowledge and awareness toward mental health also affects failure to seek help (Gong \& Furnham, 2014). Numerous psychological stresses are considered as normal and thought to be able to disappear by itself (Choudhry et al., 2016). Obstacles to seek help are related with negative perceptions toward mental health professionals (Savage et al., 2016). Help given by professionals is evaluated as useless and its effectiveness was doubted.

The stigma toward mental health is a negative factor that can prevent seeking professional help (Schnyder et al., 2017; Vally et al., 2018). Stigma labels people with symptoms as "crazy" and causes individuals to be hesitant to seek professional help (Yap et al., 2013). Individuals that internalize stigma may conceal their emotional problems because they feel uncomfortable, embarrassed, and may withdraw from discussing those problems with professional workers (Coates et al., 2018). This stigma itself is associated with a lack of understanding of what causes mental health.

Although this study adapted an instrument with good psychometric properties, there were limitations in the present study. The characteristics of the participant demographics were dominated by female participants, who were educated and come from large cities in Indonesia. The proportion of the participant's age did not sufficiently represent the age group of 19-50. Future research should consider other factors that contribute to determining attitudes of seeking professional help. Research on help-seeking requires indigenous instruments that may minimize cultural bias and reduce mental health stigmatization.

\section{Conclusion}

The evaluation of psychometric properties of the ATSPPH-SF produced a Rasch model which was consistent and satisfactory in terms of the instrument aspects, items, and respondents. This scale met the assumption of unidimensionality in measuring attitudes of seeking professional help and was free from local independence. Analysis of infit and outfit mnsq showed that all ten items had good fit with the Rasch Model. The analysis has calculated item reliability of 1 (very good), with a respondent reliability of .59 and an alpha Cronbach of .67. The PTMEA analysis produced results that all items could differentiate abilities of the respondents. The item's separation index in the instrument included special categories which showed a value as large as 20.16. However, the respondents' separation index showed that the instrument was not sensitive enough to differentiate between high-performing or low-performing respondents. The polytomous responses values in the scale were in line with the measurement model. 
Implications

Adaptation and evaluation through the Rasch model produced items of the ATSPPH-SF which can be used for numerous research that relates with seeking professional psychological help in Indonesia. This scale would give optimal information when administered on a sample with a moderate level of professional help-seeking behaviors. Users of this scale are advised to pay careful attention to the responses of male and female respondents on A02 and A09.

\section{Declarations}

\section{Acknowledgments}

Thanks to Professor E.H. Fischer (Hartford Hospital), who developed the instrument and granted permission for adaptation. We also thank Dr. Muhana Sofiati Utami (Universitas Gadjah Mada) for the advice on this project.

Funding

This research did not receive funding from any party.

Author Contribution

The first author led and designed the research. All authors collectively collected data. The first and second authors conducted data analysis. All authors wrote the manuscript and approved the final version.

Conflict of Interest

The authors declare no conflict of interest in the production of the manuscript.

Orcid Id

FA Nurdiyanto https:/ / orcid.org/0000-0003-4353-2501

Ririn Mamiek Wulandari https:/ / orcid.org/0000-0002-5333-0009

Griselda Maria Ancela Wodong https:/ / orcid.org/0000-0001-5302-8750

\section{References}

AEgisd'ottir, S., \& Gerstein, L. H. (2009). Beliefs about psychological services (BAPS): Development and psychometric properties. Counselling Psychology Quarterly, 22(2), 197-219. https: / / doi. org/10.1080/09515070903157347

Al-Darmaki, F. R. (2003). Attitudes towards seeking professional psychological help: What really counts for united arab emirates university students? Social Behavior and Personality, 31(5), 497-508. https://doi.org/10.2224/sbp.2003.31.5.497 
Azwar, S. (2018). Penyusunan skala psikologi (2nd). Yogyakarta, Pustaka Pelajar.

Bond, T. G., \& Fox, C. M. (2015). Applying the rasch model: Fundamental measurement in the human sciences (3rd). New York, Routledge.

Boone, W. J., Yale, M. S., \& Staver, J. R. (2014). Rasch analysis in the human sciences. Springer. https: / /doi.org/10.1007/978-94-007-6857-4

Call, J. B., \& Shafer, K. (2018). Gendered manifestations of depression and help seeking among men. American Journal of Men's Health, 12(1), 41-51. https:/ / doi.org/10.1177/1557988315623993

Chang, H. J., Lai, Y. L., Chang, C. M., Kao, C. C., Shyu, M. L., \& Lee, M. B. (2012). Gender and age differences among youth, in utilization of mental health services in the year preceding suicide in Taiwan. Community Mental Health Journal, 48(6), 771-780. https:/ /doi.org/10.1007/ s10597011-9470-1

Choudhry, F. R., Mani, V., Ming, L. C., \& Khan, T. M. (2016). Beliefs and perception about mental health issues: A meta-synthesis. Neuropsychiatric Disease and Treatment, 12, 2807-2818. https: //doi.org/10.2147/NDT.S111543

Coates, D., Saleeba, C., \& Howe, D. (2018). Mental health attitudes and beliefs in a community sample on the central coast in Australia: Barriers to help seeking. Community Mental Health Journal, 55(3), 476-486. https:/ / doi.org/10.1007/s10597-018-0270-8

Cohen, B.-Z. (1999). Measuring the willingness to seek help. Journal of Social Service Research, 26(1), 67-82. https://doi.org/10.1300/J079v26n01

Duncan, L. E. (2003). Black male college students' attitudes toward seeking psychological help. Journal of Black Psychology, 29(1), 68-86. https://doi.org/10.1177/0095798402239229

Elhai, J. D., Schweinle, W., \& Anderson, S. M. (2008). Reliability and validity of the attitudes toward seeking professional psychological help scale-short form. Psychiatry Research, 159(3), 320-329. https://doi.org/10.1016/j.psychres.2007.04.020

Fang, K., Pieterse, A. L., Friedlander, M., \& Cao, J. (2011). Assessing the psychometric properties of the attitudes toward seeking professional psychological help scale-short form in Mainland China. International Journal for the Advancement of Counselling, 33(4), 309-321. https: / / doi.org / 10. 1007/s10447-011-9137-1

Fischer, E. H., \& Farina, A. (1995). Attitudes toward seeking professional psychologial help: A shortened form and considerations for research. Journal of College Student Development, 36(4), 368-373.

Fischer, E. H., \& Turner, J. L. (1970). Orientations to seeking professional help: Development and research utility of an attitude scale. Journal of Consulting and Clinical Psychology, 35(1), 79-90. https://doi.org/10.1037/h0029636

Fung, K., \& Wong, Y. L. R. (2007). Factors influencing attitudes towards seeking professional help among East and Southeast Asian immigrant and refugee women. International Journal of Social Psychiatry, 53(3), 216-231. https://doi.org/10.1177/0020764006074541

Gong, A. T., \& Furnham, A. (2014). Mental health literacy: Public knowledge and beliefs about mental disorders in Mainland China. PsyCh Journal, 3, 144-158. https://doi.org/10.1002/pchj.55 
Ibrahim, N., Amit, N., Shahar, S., Wee, L. H., Ismail, R., Khairuddin, R., Siau, C. S., \& Safien, A. M. (2019). Do depression literacy, mental illness beliefs and stigma influence mental health help-seeking attitude? a cross-sectional study of secondary school and university students from b40 households in Malaysia. BMC Public Health, 19(4), 1-8. https: / / doi.org / 10.1186/ s12889-019-6862-6

International Test Commission. (2018). Itc guidelines for translating and adapting tests (second edition). International Journal of Testing, 18(2), 101-134. https: / / doi.org / 10.1080 / 15305058. 2017.1398166

Leong, F. T., Kim, H. H., \& Gupta, A. (2011). Attitudes toward professional counseling among Asian-American college students: Acculturation, conceptions of mental illness, and loss of face. Asian American Journal of Psychology, 2(2), 140-153. https://doi.org/10.1037/a0024172

Lynch, L., Long, M., \& Moorhead, A. (2018). Young men, help-seeking, and mental health services: Exploring barriers and solutions. American Journal of Men's Health, 12(1), 138-149. https:/ /doi. org $/ 10.1177 / 1557988315619469$

Mackenzie, C. S., Knox, V. J., Gekoski, W. L., \& Macaulay, H. L. (2004). An adaptation and extension of the attitudes toward seeking professional psychological help scale. Journal of Applied Social Psychology, 34(11), 2410-2433. https:/ / doi.org/10.1111/j.1559-1816.2004.tb01984.x

Marchira, C. R., Supriyanto, I., Subandi, Soewadi, \& Good, B. J. (2016). The association between duration of untreated psychosis in first psychotic episode patients and help seeking behaviors in Jogjakarta, Indonesia. International Journal of Culture and Mental Health, 9(2), 120-126. https: //doi.org/10.1080/17542863.2015.1103276

Nam, S. K., Chu, H. J., Lee, M. K., Lee, J. H., Kim, N., \& Lee, S. M. (2010). A meta-analysis of gender differences in attitudes toward seeking professional psychological help. Journal of American College Health, 59(2), 110-116. https:/ / doi.org/10.1080/07448481.2010.483714

Nunnaly, J. C., \& Bernstein, I. H. (1994). Psychometric theory (3rd editio). New York, McGraw-Hill.

Panis, M. P., Damayanti, Y., \& Keraf, M. K. P. A. (2019). Coping strategies, personality type, and help-seeking behavior for mental health problems. Journal of Health and Behavioral Science, 1(2), 98-105. https://doi.org/10.35508/jhbs.v1i2.2087

Park, S., Jeon, M., Lee, Y., Ko, Y. M., \& Kim, C. E. (2018). Influencing factors of attitudes toward seeking professional help for mental illness among Korean adults. International Journal of Social Psychiatry, 64(3), 286-292. https://doi.org/10.1177/0020764018760952

Picco, L., Abdin, E., Chong, S. A., Pang, S., Shafie, S., Chua, B. Y., Vaingankar, J. A., Ong, L. P., Tay, J., \& Subramaniam, M. (2016). Attitudes toward seeking professional psychological help: Factor structure and socio-demographic predictors. Frontiers in Psychology, 7(4), 1-10. https: / / doi. org/10.3389/fpsyg.2016.00547

Rayan, A., Baker, O., \& Fawaz, M. (2020). The psychometric properties of attitudes toward seeking professional psychological help scale-short form in Jordanian University students. Journal of Muslim Mental Health, 14(1). https:/ / doi.org/10.3998/JMMH.10381607.0014.102 
Rickwood, D., Deane, F. P., Wilson, C. J., Ciarrochi, J. V., Online, R., Wilson, C. J., Deane, F. P., Ciarrochi, J. V., \& Rickwood, D. (2005). Measuring help seeking intentions: Properties of the general help seeking questionnaire. Australian e-Journal for the Advancement of Mental Health, 4(1), 15-28. http://cjc-rcc.ucalgary.ca/cjc/index.php/rcc/article/view/265

Rickwood, D., \& Thomas, K. (2012). Conceptual measurement framework for help-seeking for mental health problems. Psychology Research and Behavior Management, 5, 173-183. https://doi.org/10. 2147/PRBM.S38707

Roskar, S., Bracic, M. F., Kolar, U., Lekic, K., Juricic, N. K., Grum, A. T., Dobnik, B., Postuvan, V., \& Vatovec, M. (2017). Attitudes within the general population towards seeking professional help in cases of mental distress. International Journal of Social Psychiatry, 63(7), 614-621. https:/ / doi. org $/ 10.1177 / 0020764017724819$

Savage, H., Murray, J., Hatch, S. L., Hotopf, M., Evans-Lacko, S., \& Brown, J. S. (2016). Exploring professional help-seeking for mental disorders. Qualitative Health Research, 26(12), 1662-1673. https://doi.org/10.1177/1049732315591483

Schnyder, N., Panczak, R., Groth, N., \& Schultze-Lutter, F. (2017). Association between mental health-related stigma and active help-seeking: Systematic review and meta-analysis. British Journal of Psychiatry, 210(4), 261-268. https://doi.org/10.1192/bjp.bp.116.189464

Seidler, Z. E., Dawes, A. J., Rice, S. M., Oliffe, J. L., \& Dhillon, H. M. (2016). The role of masculinity in men's help-seeking for depression: A systematic review. Clinical Psychology Review, 49, 106-118. https:/ / doi.org/10.1016/j.cpr.2016.09.002

Sheikh, S., \& Furnham, A. (2000). A cross-cultural study of mental health beliefs and attitudes towards seeking professional help. Social Psychiatry and Psychiatric Epidemiology, 35(7), 326-334. https: //doi.org/10.1007/s001270050246

Smith, E. V., Conrad, K. M., Chang, K., \& Piazza, J. (n.d.). An introduction to rasch measurement for scale development and person assessment. Journal of Nursing Measurement, (3), 189-206. https: //doi.org/10.1891/jnum.10.3.189.52562

Staiger, T., Waldmann, T., R'usch, N., \& Krumm, S. (2017). Barriers and facilitators of help-seeking among unemployed persons with mental health problems: A qualitative study. BMC Health Services Research, 17(1), 1-9. https:/ / doi.org/10.1186/s12913-017-1997-6

Sumintono, B., \& Widhiarso, W. (2014). Aplikasi model Rasch untuk penelitian ilmu-ilmu sosiallrasch model application for social science research]. Cimahi, Trim Komunikata Publishing House.

Tennant, A., \& Conaghan, P. G. (2007). The rasch measurement model in rheumatology: What is it and why use it? when should it be applied, and what should one look for in a Rasch paper? Arthritis Care and Research, 57(8), 1358-1362. https:/ / doi.org/10.1002/art.23108

Ursachi, G., Horodnic, I. A., \& Zait, A. (2015). How reliable are measurement scales? external factors with indirect influence on reliability estimators, In Procedia economics and finance, Elsevier B.V. https://doi.org/10.1016/s2212-5671(15)00123-9 


\section{Nurdiyanto et all || Attitudes toward Seeking Professional}

Vally, Z., Cody, B. L., Albloshi, M. A., \& Alsheraifi, S. N. (2018). Public stigma and attitudes toward psychological help-seeking in the United Arab Emirates: The mediational role of self-stigma. Perspectives in Psychiatric Care, 54(4), 571-579. https://doi.org/10.1111/ppc.12282

Vogel, D. L., Heimerdinger-Edwards, S. R., Hammer, J. H., \& Hubbard, A. (2011). "boys don't cry": Examination of the links between endorsement of masculine norms, self-stigma, and help-seeking attitudes for men from diverse backgrounds. Journal of Counseling Psychology, 58(3), 368-382. https://doi.org/10.1037/a0023688

Williams, M. W., Skogstad, P., \& Deane, F. P. (2001). Attitudes of male prisoners toward seeking professional psychological help. Journal of Offender Rehabilitation, 34(2), 49-61. https: / / doi. org/10.1300/J076v34n02_04

Yap, M. B. H., Reavley, N. J., \& Jorm, A. F. (2013). Associations between stigma and help-seeking intentions and beliefs: Findings from an australian national survey of young people. Psychiatry Research, 210(3), 1154-1160. https:/ / doi.org/10.1016/j.psychres.2013.08.029

Yu, Y., Liu, Z. W., Hu, M., Liu, H. M., Yang, J. P., Zhou, L., \& Xiao, S. Y. (2015). Mental health help-seeking intentions and preferences of rural Chinese adults. PLoS ONE, 10(11), 1-16. https: //doi.org/10.1371/journal.pone.0141889

Zanon, C., Hutz, C. S., Yoo, H., \& Hambleton, R. K. (2016). An application of item response theory to psychological test development. Psicologia: Reflexao e Critica, 29(18). https://doi.org/10.1186/ s41155-016-0040-x 